\title{
DESOBEDIÊNCIAS EPISTÊMICAS: propostas feministas e antirracistas em direção a um projeto de ciência e sociedade decolonial
}

\author{
EPISTEMIC DISOBEDIENCES: feminist and anti-racist proposals \\ towards a decolonial Science and Society project
}

\begin{abstract}
DESOBEDIENCIAS EPISTÉMICAS: propuestas feministas y antirracistas hacia un proyecto de ciência y sociedad descolonial
\end{abstract}

\section{Tayane Rogeria Lino ${ }^{1}$, Ricardo Dias de Castro ${ }^{2}$ \& Claudia Mayorga ${ }^{3}$}

RESUMO: Esse artigo objetivou apresentar uma breve contextualização da invenção da ciência moderna como projeto de conhecimento, sociedade e poder. Em seguida, apresentam-se algumas contribuições epistêmico-políticas de três campos de saber: o feminismo, o antirracismo e a decolonialidade. Esses campos foram apresentados como mobilizações que emergem de saberes e fazeres construídos nas lutas por emancipação de populações, historicamente, violentadas por sistemas de poder patriarcais, racistas e coloniais. Defende-se, por fim, a importância radical de se

1 Tayane Rogeria Lino é Psicóloga, doutora em Psicologia Social pelo Programa de PósGraduação em Psicologia da Universidade Federal de Minas Gerais (UFMG). Professora universitária no Centro Universitário UNA. É pesquisadora no Núcleo de Ensino, Pesquisa e Extensão Conexões de Saberes. tayanelino@gmail.com.

${ }^{2}$ Ricardo Dias de Castro é Doutorando em Psicologia Social pelo Programa de Pós-Graduação em Psicologia da Universidade Federal de Minas Gerais (UFMG). Professor universitário no Centro Universitário Estácio de Belo Horizonte. É pesquisador no Núcleo de Ensino, Pesquisa e Extensão Conexões de Saberes. ricardodiascastro@gmail.com.

${ }^{3}$ Claudia Mayorga é Doutora em Psicologia Social pela Universidad Complutense de Madrid, Professora do Departamento de Psicologia do Programa de Pós-Graduação em Psicologia Universidade Federal de Minas Gerais (UFMG). Coordenadora do Núcleo de Ensino, Pesquisa e Extensão Conexões de Saberes. mayorga.claudia@gmail.com. 
inspirar em propostas de conhecimentos que levem em consideração o potencial subversivo que é produzido a partir de lugares sociais e epistêmicos fronteiriços. De onde é possível não só reagir aos poderes hegemônicos, mas, sobretudo, reinventar uma nova consciência humana que se implique em desalojar, incansavelmente, o colonizador do nosso corpo-episteme que, ao mesmo tempo, é, também, colonizado.

PALAVRAS-CHAVE: feminismo, antirracismo, decolonialidadde

\begin{abstract}
This article aimed to present a brief contextualization of the invention of modern science as a project of knowledge, society and power. Then, epistemic-political contributions from three fields of knowledge are presented: feminism, anti-racism and decoloniality. These fields were presented as mobilizations that emerge from knowledge and practices built in struggles for the emancipation of populations, historically violated by patriarchal, racist and colonial power systems. Finally, it defends the radical importance of being inspired by proposals of knowledge that take into account the subversive potential that is produced from social and epistemic frontier places. Whence it is possible not only to react to hegemonic powers, but, above all, to reinvent a new human conscience that implies relentlessly displacing the colonizer of our body-episteme who, at the same time, is also colonized.
\end{abstract}

KEYWORDS: feminism, anti-racism, decoloniality

RESUMEN: Este artículo tuvo como objetivo presentar una breve contextualización de la invención de la ciencia moderna como proyecto de conocimiento, sociedad y poder. Luego, se presentan los aportes epistémico-políticos de tres campos del conocimiento: feminismo, antirracismo y descolonialidad. Estos campos fueron presentados como movilizaciones que surgen de saberes y prácticas construidas en luchas por la emancipación de poblaciones, históricamente violadas por sistemas de poder patriarcales, racistas y coloniales. Finalmente, defiende la importancia radical de inspirarse en propuestas de conocimiento que tengan en cuenta el potencial subversivo que se produce desde los lugares de frontera social y epistémica. De ahí que sea posible no solo reaccionar ante los poderes hegemónicos, sino, sobre todo, reinventar una nueva conciencia humana que implica desplazar sin descanso al colonizador de nuestro cuerpo-episteme que, al mismo tiempo, también está colonizado.

PALABRAS CLAVE: feminismo, antirracismo, descolonialidad

\title{
SOBRE CIÊNCIA, sociedade e poder colonial/moderno
}

Os séculos XV, XVI, XVII e XVIII foram marcados pelo desenvolvimento contínuo do capitalismo mercantil e pela revolução industrial; pela dominância crescente da cidade sobre o campo; pelo estabelecimento do protestantismo em 
grandes áreas do continente europeu e, também, foi um período de revolução intelectual e de rompimento com uma produção religiosa cristã católica e mitológica que marcaram os períodos anteriores da história da Europa. Nessa direção, ideais que estavam fermentando há anos finalmente amadureceram, tornando-se novos modelos de realidade física e social e começaram a compor a atmosfera epistêmica do que terminou sendo nomeado como a modernidade.

A Europa foi o contexto da Revolução Científica que, protagonizada pelos iluministas, abriu espaço para uma reorganização do método de produção de conhecimento reconhecido, até então, e os princípios da Revolução Francesa criaram condições para ideais republicanos, contrários ao Antigo Regime Absolutista, fazendo emergir a constituição da ideia de um indivíduo dotado de direitos e separado da sociedade como um todo. A cristalização do modelo trabalhista industrial-capitalista, pela Revolução Industrial, criou as lógicas das propriedades privadas e públicas, o que gerou um campo de preocupações com o espaço individual/íntimo da humanidade. Houve um aumento da produção comercial, fazendo emergir a noção de mercadoria, inclusive, embutida na força de trabalho que, agora, teria um patrão. Por fim, como oposição às ideias do feudalismo, a perspectiva liberal teve como um de seus elementos centrais a valorização do indivíduo e da sua "natureza" humana.

Ora, a modernidade, como fluxo marcado por vários movimentos históricopolíticos, como esses apresentados acima, redimensionou a sociedade de modo radical e inaugurou condições para a emergência da Ciência Moderna Iluminista. Horkheimer e Adorno (1975), ao se debruçarem sobre o conceito de Iluminismo, apresentam que a razão moderna - em uma pretensa substituição à fé e à crença do teocentrismo da Idade Média - deveria movimentar a autonomia e a liberdade dos sujeitos modernos; o que, no entanto, não se concretizou. O projeto iluminista fraquejou no que diz respeito a livrar o mundo do "feitiço" das Trevas por ter continuado a razão alienada em si mesma e a razão - tanto quando a fé permaneceu instrumentalizando os sujeitos que se mantiveram dominados. Afinal, "a autoconsciência errônea dos cientistas burgueses durante a era liberalista aparece nos mais diferentes sistemas filosóficos" (HORKHEIMER, 1975a, p. 131).

Nesse sentido, a obsessão pela verdade dos saberes e da vida - em contraponto às ditas inverdades religiosas -, levou a uma produção científica tão mitológica e dependente de fé quanto aos cânones da Igreja, na medida em que 
para se sustentar enquanto universal, a modernidade lançou mão de estratégias ideológicas com um alto potencial de "cegueira epistêmico-política". Ora, a ciência moderna europeia, que se toma como ponto epistêmico zero pretensamente - do mundo, ainda que representativa, apenas, de um território burguês, ocidental, cristão e patriarcal branco; não tem se aberto a outras visões de mundo que, também, interpretam e intervém sobre o universo. Algo que foi possível por meio de uma sistemática e global política de extermínio de outras formas de conhecimento que centralizaram a Europa como não só a melhor, mais a única fonte de visão e referência do mundo (GROSFOGUEL, 2016).

Segundo Quijano (2005), o eurocentrismo não é, apenas, a perspectiva dos europeus, mas, também, de todo o mundo que foi "eurocentralizado" a partir do capitalismo exploratório mundial produzido pela Europa. Grosfoguel (2016), nessa direção, reconhece quatro genocídios/epistemicídios ${ }^{4}$, ao longo do século XVI, que se desdobraram na fundação da estrutura epistêmica da ciência moderna e das universidades ocidentalizadas que se nutrem, fortemente, da ideia da Europa patriarcal e racista como centro. O que teve como consequência a naturalização da idolatria ao método cartesiano monopolizando a autoridade do conhecimento no/do mundo como sendo de origem europeia. Isto é, vários conhecimentos foram exterminados para que a ciência ocidental europeia se sustentasse como epistemologia-método universal de conhecimento. "Como é que no século XXI, com tanta diversidade epistêmica existente no mundo, estejamos ancorados em estruturas epistêmicas tão provincianas camufladas de universais?" (GROSFOGUEL, 2016, p. p.27).

A modernidade/colonialidade, portanto, tem sido projeto que alicerça a construção das universidades no mundo ocidentalizado - com um efeito nefasto, sobretudo, na sociedade latino-americana - que tinham, então, o compromisso de disseminar conhecimentos e formas de ensino superior que tomassem como centro a universidade renascentista europeia. Colaborou-se, desde então, para o

\footnotetext{
${ }^{4}$ Os racismos/sexismos epistêmicos que marcam a produção do conhecimento científico ocidental/ocidentalizado. O que, por sua vez, segundo Grosfoguel, estruturou-se por meio do genocídio/epistemicídio contra muçulmanos e judeus na conquista de Al-Andalus, contra povos nativos na conquista das Américas, contra povos africanos na conquista da África e a escravização dos mesmos nas Américas e, finalmente, contra as mulheres europeias queimadas vivas acusadas de bruxaria.
}

Cadernos de estudos culturais, Campo Grande, MS, v. 2, p. 209-226, jul./dez. 2020. 
reforçamento da hegemonia canônica do Ocidente como padrão de conhecimento mundial. Sendo assim, a universidade, em qualquer lugar do mundo, torna-se não só o espaço privilegiado para a produção do conhecimento, mas se estabelece, também, como a grande instituição republicana capaz de estabelecer os limites entre o saber legítimo (ciência) e ilegítimo (senso comum), bem como aquela que seria capaz de produzir uma prática de pensamento - tida como superior - que pudesse avaliar o passado, o presente e o futuro da vida em sociedade (BRINGEL E VARELLA, 2016).

Contudo, é fato desde a implantação da matriz colonial de ser, saber e poder (MALDONADO TORRES, 2007), há vários movimentos que questionam, a partir da diferença colonial, a racionalidade moderna, na tentativa de se criar um pensamento crítico. E, sendo assim, para que não sejamos reféns totais e acríticos das contingências dessa postura moderna de pensar o conhecimento e a relação com a sociedade da universidade pública, cabe a nós, resistir a essa lógica epistemicida. E para resistir é preciso apostar em modelos alternativos de saber/fazer conhecimento, resgatando tradições críticas e (re)construindo outros conhecimentos que transcendam a hegemonia da modernidade/colonialidade europeia que, em sua história de séculos, não convocou populares, mulheres, africanos e indígenas para o jogo do saber/poder da ciência (GROSFOGUEL, 2016).

No entanto, ainda que o projeto colonial de genocídio/epistemicídio, certamente, tenha sido bem-sucedido; ele não um projeto total. De fato, seria impossível, diante de cinco séculos de colonização do saber/existir, conceber alguma produção moderna e contemporânea que esteja, totalmente, fora da modernidade eurocêntrica. Ao mesmo tempo, ainda que as tradições culturaisepistêmicas estejam atravessadas pela colonialidade do saber/poder, têm perdurado perspectivas e projetos que não são, propriamente, ocidentais e que não foram, completamente, destruídos (GROSFOGUEL, 2016). É a partir desse local tenso e paradoxal e sempre em movimento que optamos por reconhecer e valorizar a esperança em mundo que seja possível para além dos pactos modernos/coloniais, patriarcais e racistas.

Para esse artigo, escolheremos apresentar dois campos-projetos que têm se tornado cada vez mais protagonistas nas discussões epistêmicas e políticas dos campos progressistas em ciência: o feminismo e o antirracismo. Em seguida, concluiremos a nossa argumentação apresentando a importância de se pensar uma 
prática científico-política que assuma o seu caráter revolucionário nas fraturas da própria colonização. Sobretudo, quando precisamos levar em consideração os efeitos violentos de uma política eurocêntrica em territórios latino-brasileiros tão, marcadamente, violado em sua pluralidade, mas que, também, oferece resistências a partir das diversas cosmovisões de seus distintos povos e de seus conhecimentos.

\section{AS TEORIAS FEMINISTAS como desobediência epistêmica}

O movimento feminista em sua expressão acadêmica, social e política aponta que a história, que angariou status de verdade, foi uma história dos homens. $\mathrm{O}$ que faz com que elas comecem a reivindicar uma história contada a partir do lugar social das mulheres. Ao afirmarem que as mulheres foram subalternizadas e invisibilizadas no processo de produção da história, além de, terem sido impedidas de desenvolver um como fazer neste contar e re-contar, sendo construídas como o "outro", "o não falante", as feministas buscaram lançar mão de um novo conjunto de discursos que desconstroem a narrativa da "história universal" tal como foi escrita, e substituí-la por narrativas escritas sob o ponto de vista das mulheres. A denúncia do silêncio ruidoso das mulheres (PERROT, 1992) lança as feministas na busca de quem é o sujeito da história. Esta procura repercutiu também sobre os sujeitos produtores das "verdades", o que resultou em uma ruptura com o pacto de silêncio na produção científica. Pacto este que foi essencial na produção tal como vemos hoje (FOUCAULT, 2004).

O lócus de produção de compreensões científicas sobre a realidade hoje conhecido como epistemologias feministas, vêm sendo construído desde a década de 1970, no bojo da segunda onda do movimento feminista ${ }^{5}$, a partir dos estudos de gênero acerca do lugar social da mulher na ciência. Esse debate tem sido realizado, principalmente, por mulheres que se dedicaram aos estudos das

\footnotetext{
${ }^{5}$ Lançamos mão dessa narrativa tendo em vista o seu caráter pedagógico-analítico e não a sua naturalização como verdade do feminismo. Afinal, essa narrativa, em ondas, tem sido pensada a partir do protagonismo das mulheres do Norte Global ocidentalizado - Estados Unidos e Europa - e deve ser, amplamente, questionada como narrativa única.
} 
epistemologias, que em sua forma mais ampla, pode ser definida como o estudo do conhecimento e dos modos de conhecer. Nesse sentido, a expressão "epistemologia feminista" se refere a uma vertente de análise da ciência a partir de marcadores sociais, com foco na influência das questões de gênero na produção científica.

Grande parte das epistemólogas feministas (HARAWAY, 1995; LUGONES, 2014;) argumentaram que o conhecimento não pode ser dissociado do tempo, do sujeito e lugar de sua produção. Dessa forma, destacaram que as hierarquias de gênero - representada na dominação masculina e na subalternidade feminina - têm influências diretas na forma como a ciência é construída e organizada. Estes estudos apontavam, por exemplo, a existência de um silenciamento das vozes femininas e uma ausência e/ou invisibilidade das mulheres nas pesquisas, algo que permitiu questionar os princípios tradicionais da ciência: a objetividade, neutralidade e a universalidade.

O modelo científico moderno hegemônico foi alvo de duras críticas por parte do pensamento feminista e de outras teorias e campos de estudo. A legitimidade de uma pesquisa sem um sujeito que se enuncie foi questionada, tal como a crença nas dicotomias corpo-mente, razão-emoção e sujeito-objeto. As conclusões feministas sobre o "como" e "por que" fazer ciência apontam para a denúncia da unicidade do sujeito da ciência, sendo este masculino. O fazer científico hegemônico se estruturou, conforme dito anteriormente, segundo as teóricas feministas, na tríade: universalidade, objetividade e neutralidade. As teóricas feministas ao se debruçarem sobre os mecanismos epistemológicos e metodológicos que, por muito tempo, invisibilizaram qualquer reconhecimento à produção de mulheres na ciência, tiveram como resposta feminista a pluralidade de possíveis produtores/as de verdades a partir da proposição de uma nova tríade explicativa: posicionamento, reflexividade e criticidade (NEVES \& NOGUEIRA, 2005).

Esta outra tríade se dá a partir da experiência, categoria redimensionada pelas teóricas feministas. No contexto contemporâneo, assim como neste estudo, o papel das experiências ocupa lugar privilegiado de discussão nos processos de compreensão da produção do conhecimento que vai de encontro à ideia de objetividade e de sujeito universal. A noção de experiência aborda a relação entre subjetividade, política, conhecimento e linguagem. Esta por sua vez pode apresentar-se, não apenas como uma fonte da saber, mas também, como um ponto 
de partida para uma outra prática acadêmica. É a partir da ideia de experiência como uma categoria analítica que se tem compreendido os processos de subjetivação do pesquisador e da pesquisadora, evidenciando como a posição de sujeito e as experiências distintas interferem na produção do conhecimento. Nestes termos "identificar a experiência que existe por detrás da produção de saber, da construção de verdades e da prescrição de projetos de sociedade é também do que tratam os feminismos. Lançar luz à experiência é, sobretudo, conferir posição e materialidade ao poder" (DINIZ, 2013, p.28).

A reflexividade é uma tentativa não ingênua de explicitar as relações de poder no processo investigativo, que se atenta às contingências históricas, políticas e sociais da produção do conhecimento (RAMAZANOGLU \& HOLLAND, 2002). Uma análise reflexiva na produção científica reconhece que o conhecimento é emoldurado por quadros de referência sócio-políticos.

O posicionamento, tão recorrente nos textos feministas, ganha roupagem nas proposições de Haraway (1995). Para a autora, a experiência é motor para a construção de sentidos e significados, a sua inscrição no mundo real, no campo científico e político se dá na experiência, e assumir uma postura ética diante de uma produção é antes te tudo localizar-se. É a partir do posicionamento que os códigos de inteligibilidade, solidariedade e antagonismos são postos na mesa e entram no jogo da produção científica. As posições ocupadas pelos sujeitos na disputa por regimes de verdades não foram vistas fora de um campo de poder. Nesse sentido, as categorias de gênero, raça, origem e orientação sexual importam, evidenciando que o conhecimento está intimamente vinculado com a biografia e a experiência pessoal de vida do sujeito epistêmico (BACH, 2010) sendo uma posição crítica diante do conhecimento. A objetividade máxima de um conhecimento é, justamente, a certeza de sua visão corporal e parcial; contrapondo-se, assim, à "visão de lugar nenhum" da pretensa neutralidade da modernidade/colonial. A (auto)crítica, nessa direção, torna-se fundamental, no exercício da perspectiva parcial, já que precisamos nos tornar responsáveis pelo que aprendemos a ver (HARAWAY, 1995; SARDENBERG, 2002).

É importante reiterar que as experiências, historicamente, subalternizadas pelo poder patriarcal não podem ser, nunca, alocadas como ontologias da resistência política, uma vez que ainda que elas sirvam como uma "pista visual" privilegiada sobre a compreensão-intervenção nas relações de poder no mundo; 
elas, também, não estão isentas de reavaliação crítica. Afinal “identidade, incluindo auto-identidade, não produz ciência; posicionamento crítico produz (...)" (HARAWAY, 1995, p. 27).

E é, justamente, esse movimento de autocrítica constante que tem tornado feminismo um movimento tão plural e diverso na medida em que repensa a si mesmo. As distinções/desigualdades que recaem sobre os diferentes símbolos de construção entre mulheres brancas e mulheres negras, por exemplo, é o que tem sido a força motriz para a organização de um conhecimento e de uma prática política que tensione com a ideia de uma mulher universal. Dessa forma, a problemática racial surge com força, no bojo do feminismo, para que se houvesse uma racialização do gênero, na medida em que as experiências de mulheres brancas e negras não são as mesmas. Aqui, inicia-se uma preocupação em se retomar a especificidade da violência contra a mulher negra e, sobretudo, a rememorar a história de luta das mulheres negras, desde a escravidão até o momento contemporâneo (CANUTO, 2015).

$\mathrm{O}$ fato de as mulheres negras estarem situadas na alteridade colonial de homens e de brancos, muitas vezes, fizeram com que elas se vissem sem um lugar de representatividade tanto no feminismo hegemônico quanto no movimento negro. O efeito da dupla exclusão - tripla, se somarmos a ideia de classe - tem levado as mulheres negras feministas a terem um compromisso epistêmicopolítico em se pensar e intervir sobre as opressões de forma interligada (DAVIS, 2016).

\section{EPISTEMOLOGIAS ANTIRRACISTAS: movimentos negros que (nos) reeducam}

As populações negras escravizadas, desde que o primeiro grupo negro foi trazido sequestrado da África para as Américas, duvidaram de que o modelo colonial fosse projeto de vida digno para qualquer comunidade. Com o tráfico de distintos povos e culturas do continente africano para distribuição pela costa americana, traficaram-se, não, apenas, corpos para o trabalho forçado, o que por si só é horrendo. Traficaram-se sonhos, projetos, saberes de todas as formas (médicos, arquitetônicos, gastronômicos e etc...), tecnologias, pensamentos, cosmovisões, espiritualidades, sexualidades, culturas e todo e qualquer elemento que compõe a experiência histórico-criativa de sujeitos que vive em sociedade.

Cadernos de estudos culturais, Campo Grande, MS, v. 2, p. 209-226, jul./dez. 2020. 
Essas mesmas populações negras foram capazes de se organizar individual e, sobretudo, coletivamente para questionarem o sistema escravocrata e lutarem por um mundo onde a lógica colonial fosse, radicalmente, derrubada em direção a um projeto, racialmente, democrático de sociedade. Desde as revoltas do período colonial, atravessando as insurreições iniciais da república e até o momento contemporâneo, negras e negros afro-brasileiros foram capazes de politizar as suas experiências para reivindicarem outros modelos de vida e de pactos coletivos em que as diferenças humanas não precisassem ser tratadas como hierarquias e desigualdades.

Toda essa movimentação em torno de lutas por emancipação desses povos, historicamente, violentados por um sistema de poder colonial, produziu uma infinidade de saberes e fazeres questionadores, críticos e, também, propositivos para toda a humanidade (GOMES, 2017). Humanidade essa, que a partir da centralização da modernidade europeia, cindiu o mundo entre aqueles que seriam mais humanos (homens, brancos, burgueses, europeus, heterossexuais, entre outros) e menos humanos (negros, ameríndios, mulheres, latino-americanos, asiáticos, africanos, entre outros). A partir de estratégias que se constituíram por meio de uma trajetória sócio-política diaspórica, as populações negras escravizadas, alforriadas e livres sempre estiveram em tensão com o projeto de se e existir que toma a Europa como centro da humanidade.

O que teve como efeito a construção de um campo de tensão que, quer nós queiramos ou não, influenciou a sociedade brasileira em todos os seus âmbitos. Os saberes e fazeres que foram traficados e apropriados pelo tráfico de negros nunca deixaram de ser, também, expressões autênticas das cartografias epistêmicas dessas populações. Isto é, ainda que a população branca colonial se apropriasse, indevidamente, do conhecimento afro-brasileiro, negros e negras tensionaram com esse jogo perverso, inclusive, escolhendo como jogá-lo. Justamente, para continuarem mantendo o protagonismo de seus referenciais intelectuais na preservação e nas transformações de seus pactos culturais que se encontram presentes em nossos corpos, linguagens, hábitos alimentares, musicalidade, sincretismo religioso, saberes científicos e etc....

Reconhece-se, aqui, o papel educador que os movimentos negros e os intelectuais antirracistas - as mulheres aí incluídas - têm construído enquanto produtores de saberes emancipatórios que, inclusive, transformaram-se em 
reivindicações, das quais várias se tornaram políticas de Estado nas primeiras décadas do século XXI (GOMES, 2017).

Os saberes negros, nesse sentido, são tomados tanto como sinônimo de escolaridade, a partir de uma perspectiva instrumental, quanto em seu sentido mais amplo, o que inclui a valorização de suas cosmovisões e símbolos culturais como referência de conhecimento. A educação, como campo de formação humana, então, ocupou um papel de destaque na estratégia de luta do movimento negro, sendo vista de diversas maneiras: como pré- requisito de acesso à sociedade civilizada e moderna; como mecanismo capaz de equiparar os negros aos brancos, conferindo-lhes oportunidades iguais no mercado de trabalho; como condição básica para a inclusão e consequente mobilidade social; como instrumento de conscientização por meio do qual os negros aprenderiam a história de seus ancestrais e se conectariam com os valores positivos da negritude (DOMINGUES, 2009).

Toda essa disputa em torno da importância de um sistema educacional em que os negros possam ter os seus acessos garantidos, ao mesmo tempo, em que lutam por um enegrecimento epistêmico desse mesmo sistema, culminou na construção de um debate em torno da democratização da ciência e do ensino superior conhecido, internacionalmente, como Ações Afirmativas.

As epistemologias antirracistas, nessa direção, defendem uma postura que aponta para uma espécie de uma nova forma de organização cultural, autêntica e na direção de um projeto de sociedade que seja capaz de contemplar toda expressão de vida e, portanto, de conhecimento e ciência, de forma, racialmente, democrática. Ou seja, há uma política afirmativa acadêmica atual que tem partido de pressupostos que colocam em xeque o brancocentramento e a Europa como o único local possível para a produção da ciência. E, sendo assim, a política afirmativa busca restaurar e preservar a humanidade e dignidade das produções humanas; sejam elas de descendência africana ou não. Sem que caiamos, no entanto, em um discurso que equalize as contribuições de cada matriz cultural brasileira; como se brancos e não-brancos fossem valorizados da mesma forma na nossa identidade nacional. Certamente, é preciso que não priorizemos nenhuma forma de saber sobre outra, mas isso não poderá ser feito negando as desigualdades históricas entre as contribuições intelectuais africanas, de um lado e europeias, de outro, para a formação do campo do conhecimento no mundo e no 
Brasil (GROSFOGUEL，2016; GUIMARÃES，2016; NASCIMENTO，2016; NOGUEIRA 2014).

Em um país em que os negros são associados às mais diversas carências (econômicas, culturais, morais, materiais, estéticas, religiosas e simbólicas); tomar a universidade latino-brasileira como um lugar de poder que, sócio ideologicamente, foi construído por brancos e para brancos de uma elite financeira colonial e escravagista, é primordial para que nos interroguemos sobre as possibilidades que a comunidade acadêmica atual têm de furar a universidade e a sociedade na direção de horizontes mais democráticos e menos marcados por eixos coloniais no campo do saber (SCHUCMAN, 2012). O que coloca em disputa não apenas o que os negros podem ser na sociedade, mas, sobretudo, redireciona o próprio horizonte de sociedade que desejamos.

Sendo assim:

As ações afirmativas devem ser compreendidas, para além de uma política de reserva de vagas para pobres, um projeto societário que garanta que sujeitos, compulsória e historicamente, expulsos da universidade; possam ter os seus saberes, práticas e vivências considerados um campo de saber/viver legítimo. Um campo que redimensione as verdades e as violências (brancocentradas e elitistas) que, historicamente a universidade sedimentou como sendo a sua única face. Sendo assim, enquanto a universidade continuar sendo um local sagrado de suposto saber e de propagações técnico-ideológicas que produz des(naturalizações) que des(humanizam) os descendentes afro-brasileiros; ela será o alvo da interpelação de práticas, críticas e perspectivas, epistemo e politicamente, enegrecidas (CASTRO \& MAYORGA, 2018, p. 198).

Há, inevitavelmente, em todos esses anos de (re)existências negras diaspóricas, no Brasil, saberes produzidos pela comunidade negra organizada e que foram sistematizados pelo Movimento Negro Brasileiro. Evidenciando, no cenário, público, a criação engajada de uma forma de conhecer o mundo, duvidar dele, racializá-lo e intervir sócio, cultural e politicamente em suas relações. É interessante apontar que, dentre várias dessas produções intelectuais e políticas, há três que se destacam. São eles: os saberes identitários - o que aponta para uma nova visibilidade da questão racial de forma afirmativa e propositiva, os saberes políticos - que demonstram a entrada das discussões antirracistas pelas instituições republicanas e, por fim, há os saberes estético-corpóreos - que engendram uma politização da estética como arma de reconhecimento e redistribuição material e simbólico (GOMES 2017). 


\section{ALGUMAS SÍNTESES PROVISÓRIAS: o feminismo decolonial como projeto de sujeito, sociedade e ciência}

Não queremos escorregar em um desconstrutivismo científico paralisante e maniqueísta, afinal não se pretende, com a nossa argumentação, a saída do próprio campo científico que, aos nossos saberes e práticas, é o que está em disputa. A ciência, portanto, corresponde a uma compreensão do mundo que é, sempre, contestável na medida em que nenhuma experiência está totalmente autorizada a uma compreensão universal dos fenômenos.

Os movimentos de produção de sentido científico contra-hegemônico antirracista e antissexista têm se construído como uma tarefa de ruptura com o olhar imperialista, em busca da configuração de um conjunto de pensamentos de desconstruções e de questionamento ao modelo científico moderno proposto pelo norte global como um olhar universal sobre a realidade, mas em verdade, são mainstream, manstream e whitestream.

Ademais, a própria lógica colonial/moderna embebeu-nos de uma lógica não só, violentamente, sexista e racista, mas, também, submetida aos desejos econômico-políticos do Norte Global. Nessa direção, o feminismo e o antirracismo, como movimentos epistêmicos, precisam tensionar com a hegemonia branca/europeia/norte-americana nas proposições feministas e, também, com a hegemonia masculina e nortista que sustentam as vozes antirracistas pelo mundo.

É preciso lutar, radicalmente, por outras maneiras de saber/fazer e, fundamentalmente, existir. As práticas científicas construídas, no bojo da luta das marginais pelo capitalismo moderno/colonial globalizado, precisam se implicar com a reflexividade feminista, com a desconstrução aos feminismos canônicos do Norte Global, apostando na perspectiva das mulheres não hegemônicas. Nessa direção, é preciso criticar, constantemente, nossas posições como produtores de conhecimento, convocando-nos a uma diversidade de atrizes sociais que, também, possam ser coprotagonistas de saberes e fazeres importantes para a sociedade (HOOKS, 2013).

Lugones (2014), a partir das epistemologias de mulheres negras e do Sul Global, reinsere o debate da interseccionalidade - raça, classe, sexualidade e 
gênero - junto à colonialidade do poder; em um movimento de crítica ao feminismo hegemônico e, também, ao movimento decolonial - protagonizado por Quijano (2005) - que não tomou o gênero com a mesma centralidade da raça. Para a autora, isso significa que a imposição colonial do gênero foi fundamental, não só para a organização dos corpos e sexualidades das mulheres e dos colonizados através de uma subordinação sexual, mas, também, no que tange questões sobre ecologia, economia, governo, espiritualidade, conhecimento e o cotidiano nas colônias.

Essa fratura colonial que é racial, mas, também, de gênero é o que tem permitido que povos colonizados se submetam às dicotomias modernas de modo assujeitado; mas que, também, através de uma subjetividade ativa, agencie respostas estratégicas de decolonização. A resistência, a partir de uma perspectiva feminista decolonial, é o ponto de partida para as análises das experiências econômicas, raciais e de gênero dos povos colonizados: é onde demos habitar, em suas palavras. É a partir desse lócus fraturado que podemos enfrentar os movimentos reflexivos, criativos, comportamentais, epistêmicos, políticos daqueles que antagonizam com a lógica colonial. Isto é, projetos de sujeito e de sociedade são reinventados, continuamente, nessas fronteiras. E, sendo assim, Lugones (2014) propõem que vejamos com bons olhos a multiplicidade na fratura do lócus: desde a atualização da colonialidade do gênero quanto a resposta de resistência a partir do lugar subalterno. Sendo preciso romper com o projeto colonial como algo dado e enfrentar a tensão entre a desumanização e a paralisia da colonialidade do ser e a atividade criativa de "ser-sendo" (LUGONES, 2014).

Essa é uma brecha epistêmica-política embebida em perigos e armadilhas tendo em vista que desalojar o colonizador do nosso corpo, ambivalentemente também colonizado, tem sido um desafio cotidiano; mas não prescritível. Propomos, nesse sentido, a construção de uma ciência prudente que se volte para conhecimentos que lidem, diretamente, com os sujeitos que não foram convocados ou participam muito pouco do contrato social moderno/colonial no qual a ciência foi forjada. Sobretudo, em território latino-brasileiro. Entrar em contato com as demandas e propostas com as ditas minorias sociais, grupos marginalizados e excluídos, tomando-os como atores sociais, é recusar uma postura assistencialista e vitimizante de suas experiências. E, por outro lado, sustentar uma relação que os vejam como seres lúcidos, "munidos de uma vantagem cognitiva de pensamento lateral comparada com os incluídos" (p.6) Isto é, os subalternizados podem e devem ser convocados a se expressarem de forma 
autêntica, justamente, porque a potência de suas contribuições reside no fato de que eles se encontram nas fronteiras da exclusão, fora muros da universidade; sendo, portanto, menos "integrados" e "institucionalizados" (CARVALHO, 2004).

Sendo assim, as histórias de experiências das subalternas, quando politizadas e compreendidas como campos de visões legítimos - jamais únicos e totais do mundo - denunciam que todo saber é proveniente de um corpo que experencia esse mundo e produz um sentido sobre ele. É preciso apostar nas desobediências epistêmicas e políticas daqueles que se encontram para além da totalidade moderna. Sendo assim, a ciência e a sociedade ganham quando nos inspiramos na figura da Mestiza (ANZALDUA, 2005). O que quer dizer que devemos recusar atuar, apenas, a partir da reação ao poder, uma vez que reagir é, de alguma forma, estar subordinada àquilo contra o qual se está reagindo. As respostas diretas ao poder central não podem ser um meio de vida para sempre. É preciso mais do que isso. Para a Mestiza, é preciso assumir, rumo a uma nova consciência epistêmica e política, que precisaremos sair das margens opostas que antagonizam com as estruturas "do lado de lá", para sermos, também, estruturas junto a "eles". A mestiza, como sujeita da resistência, duvida da possibilidade de sustentar conceitos e ideias dentro de limites rígidos; mantendo-se, por outro lado, flexível, movendo-se para fora das formações dicotômicas e cristalizadas da modernidade, tendo um prazer pelo contraditório.

É preciso fazer um esforço político para reconhecer como audíveis - e não como ontologias da razão - as vozes daquelas que desobedecem às normas modernas, as vozes inapropriadas ${ }^{6}$. Na medida em que elas se encontram fora dos modelos hegemônicos, ao mesmo tempo que, também, os conhecem muito bem. Afinal, é por esse poder que elas são, comumente, capturadas e é, de dentro desse mesmo poder que elas optam por (se) subverterem à lógica (COLLINS, 2016). Nesse contexto, é preciso apostar em um projeto de humanidade em que se multipliquem conexões em que um se reconheça no outro e veja, na semelhança, diferença e, na diferença, semelhança. "A universalidade reside nessa decisão de

\footnotetext{
${ }^{6}$ Termo retirado da produção: hooks, B., Brah, A., Sandoval, C., Anzaldúa, G., Levins Morales, A., Bhavnani, K. K., ... \& Talpade Mohanty, C. (2004). Otras inapropiables: Feminismos desde las fronteras. Madrid: Traficantes de sueños, 2004.
}

Cadernos de estudos culturais, Campo Grande, MS, v. 2, p. 209-226, jul./dez. 2020. 
assumir o relativismo recíproco de culturas diferentes, uma vez excluído irreversivelmente o estatuto colonial" (FANON, 1968, p. 48).

É preciso não ter medo de renunciarmos aos nossos pactos narcísicos (BENTO, 2002) para nos permitirmos, então, ovacionarmos o impacto positivo do saberes não-europeus, feministas e enegrecidos no mundo; uma vez que o saber ocidental, historicamente, objetificou aquele que foi tomado como "o outro". E o sintoma mais evidente de que esse é o cerne de construção da ciência é a ausência e/ou dificuldades desses "outros" em uma versão mais tradicional de ciência e sociedade. A práxis feminista negra decolonial, diante desse cenário, abraça o potencial epistêmico da marginalidade das mulheres negras latino-brasileiras, tendo como horizonte a liberdade à diferença, ao mesmo tempo, em que se defende a solidariedade humana. Isso porque o movimento contra-hegemônico do feminismo negro decolonial, ainda que partindo da experiência das mulheres negras colonizadas, direciona-se a um novo projeto de rehumanização da sociedade e do conhecimento como um todo (COLLINS, 2016).

É preciso, por fim, transformar as ambivalências modernas em um desejo de saber/fazer conhecimento que reconheça a necessidade urgente da (re)construção de um mundo que seja melhor a todos e todas. Um mundo em que seja possível se reconhecer, subjetiva, epistêmica e socialmente semelhante (nunca igual ao outro) e, também, a partir da diferença (jamais da desigualdade).

\section{Referências Bibliográficas}

ANZALDÚA, Gloria. La conciencia de la mestiza: rumo a uma nova consciência. Revista estudos feministas, v. 13, n. 3, p. 704-719, 2005.

BENTO, Maria Aparecida da Silva. Pactos narcísicos no racismo: branquitude e poder nas organizações empresariais e no poder público. 2002. Tese de Doutorado. Universidade de São Paulo.

BERNARDINO-COSTA, Joaze; GROSFOGUEL, Ramón. Decolonialidade e perspectiva negra. Sociedade e Estado, v. 31, n. 1, p. 15-24, 2016.

BRINGEL, Breno; VARELLA, Renata Versiani Scott. A pesquisa militante na América Latina hoje: reflexões sobre as desigualdades e as possibilidades de produção de conhecimentos. Revista Digital de Direito Administrativo, v. 3, n. 3, p. 474-489, 2016. 
CANUTO, Alice de Alencar Arraes. (Re) visitando personagens, cenários e vozes: nas tramas sobre o sujeito do feminismo no Blogueiras Feministas. 2016.

CARVALHO, José Jorge. A prática da extensão como resistência ao eurocentrismo, ao racismo e à mercantilização da universidade. Departamento de Antropologia, Universidade de Brasília, 2004.

COLLINS, Patricia Hill. Aprendendo com a outsider within: a significação sociológica do pensamento feminista negro. Sociedade e Estado, v. 31, n. 1, p. 99-127, 2016.

DAVIS, Angela. Mulheres, raça e classe. Boitempo Editorial, 2016.

DOMINGUES, Petronio. O recinto sagrado: educação e antirracismo no Brasil. Cadernos de Pesquisa, v. 39, n. 138, p. 963-994, 2009.

FANON, Frantz. Os condenados da Terra. Civilização Brasileira, 1968.

FOUCAULT, Michael. (2004). "Os corpos dóceis"- Vigiar e punir: nascimento da prisão. (trad. Raquel Ramalhete). Petrópolis, RJ: Vozes.

GROSFOGUEL, Ramón. A estrutura do conhecimento nas universidades ocidentalizadas: racismo/sexismo epistêmico e os quatro genocídios/epistemicídios do longo século XVI. Sociedade e Estado, v. 31, n. 1, p. 25-49, 2016.

GUIMARÃES, Antonio Sérgio Alfredo. Formações nacionais de classe e raça. Tempo Social, v. 28, n. 2, p. 161-182, 2016.

HOOKS, bell. (1995). Intelectuais negras. Revista Estudos Feministas, 3 (2), 464-478.

HOOKS, Bell. Ensinando a transgredir: a educação como prática da liberdade. São Paulo: Editora WMF Martins Fontes, 2013.

HORKHEIMER, M. (1975a). Teoria Tradicional e Teoria Crítica In: W. Benjamin, M. Horkheimer, T. W. Adorno, J. Habermas (org.). Textos Escolhidos. São Paulo: Abril Cultural (Coleção Os Pensadores).

LUGONES, María. Rumo a um feminismo descolonial. Revista Estudos Feministas, v. 22, n. 3, p. 935-952, 2014.

MALDONADO-TORRES, Nelson. Sobre la colonialidad del ser: contribuciones al desarrollo de un concepto. El giro decolonial. Reflexiones para una diversidad epistémica más allá del capitalismo global, p. 127-167, 2007.

NASCIMENTO, Abdias. O genocídio do negro brasileiro: processo de um racismo mascarado. Editora Perspectiva SA, 2016. 
NEVES, Sofia; NOGUEIRA, Conceição. Metodologias feministas: a reflexividade ao serviço da investigação nas ciências sociais. Psicologia: reflexão e crítica, v. 18, n. 3, p. 408-412, 2005.

NOGUEIRA, S.G. (2014). Políticas de Identidade, Branquitude e Pertencimento étnicoracial. In: Identidade, Branquitude e Negritude - Contribuições para a Psicologia Social no Brasil: Novos Ensaios, Relatos de Experiência e de Pesquisa. Bento, M., Silveira, M., Nogueira, S. (Org). São Paulo: Casa do Psicólogo.

QUIJANO, Aníbal. Colonialidade do poder, eurocentrismo e América Latina. In. LANDER, Edgardo (Org.). A colonialidade do saber: eurocentrismo e ciências sociais: perspectivas latinoamericanas. Ciudad Autnoma de Buenos Aires, Argentina: Clacso, 2005.

Artigo recebido em: 30 de setembro de 2020. Artigo Aprovado em: 28 de dezembro de 2020. 